\section{Antioxidant Capacity and Phenolic Content of Selected Strawberry Genotypes}

\author{
Djamila Rekika, Shahrokh Khanizadeh, ${ }^{1}$ Martine Deschênes, Audrey \\ Levasseur, and Marie Thérèse Charles \\ Agriculture and Agri-Food Canada, Horticultural Research and Development \\ Centre, 430 Boulevard Gouin, St-Jean-sur-Richelieu, QC, Canada, J3B 3E6
}

\author{
Rong Tsao and Raymond Yang \\ Agriculture and Agri-Food Canada, Food Research Centre, 93 Stone Road \\ West, Guelph, ON, Canada, N1G 5C9
}

Additional index words. Strawberry, total phenolic content, antioxidant, TEAC, FRAP, phenolic composition, shelf life, breeding and disease resistance.

\begin{abstract}
Eighteen strawberry genotypes were evaluated for their phenolic content and antioxidant capacity using several methods. High antioxidant capacity was found for 'Harmonie', 'Saint-Jean d'Orléans', and 'Saint-Laurent d'Orléans', which were reported to have better shelf life than 'Kent'. 'Harmonie', 'Saint-Jean d'Orléans', 'Orléans', and some advanced selections had higher hydroxycinnamic acids, benzoic acids, and flavonols than 'Kent'. The significant variation in antioxidant capacity and total phenolic compounds clearly shows the potential value of certain new cultivars and advanced lines as parents in a breeding program. The future plan is to examine individual antioxidant and their role in disease resistance and extension of shelf life and to use selected genotypes as parents to developed new lines.
\end{abstract}

For the past few years, growing interest has been devoted to the phytochemical content of raspberry (Rubus idaeus L.), blueberry (Vaccinium sp.), strawberry (Fragaria ananassa Deuch.) and other fruits (Clark et al., 2002; Maas et al., 1991; Kalt et al., 2001; Prior et al., 1998; Wang and Lin 2000) and specific attention has been given to the antioxidant capacity of these fruits. Conclusive evidences were drawn from the cited studies demonstrating that antioxidant vitamins such as vitamin $\mathrm{C}$, vitamin $\mathrm{E}$, or $\beta$-carotene were not the only compounds responsible for the antioxidant capacity of the studied fruits and vegetables. Other studies showed that antioxidant activity of plant extracts, like grape (Vitis vinifera L.), blueberry and strawberry was correlated with total phenolic content rather than with any individual phenolic compound (Meyer et al., 1997; Prior et al., 1998; Wang et al., 1997). In strawberry fruit, ellagic acid along with some flavonoids (anthocyanins, proanthocyanins, catechin and isocatechin) are the main compounds with antioxidant properties. These compounds are known to influence quality, acceptability and stability of foods by acting as flavorants, colorants or antioxidants (Maas et al., 1991).

The antioxidant capacity and the composition of bioactive compounds in fruits and vegetables are influenced by several factors of which the most commonly cited are cultural practices, preharvest conditions (climate,

Received for publication 10 Nov. 2004. Accepted for publication 5 Apr. 2005. Agriculture and Agri-Food Canada, St-Jean-sur-Richelieu, contribution.

${ }^{1}$ To whom all correspondence should be addressed; e-mailkhanizadehs@em.agr.ca. temperature), maturity, post-harvest handling and processing (Clark et al., 2002; Kalt et al., 2001; Prior et al., 1998; Saure, 1990; Wang and Zheng, 2001; Wang et al., 2002). Substantial variation has been observed in strawberry for ellagic acid content (Funt et al., 2001) and in blueberry for antioxidant capacity and anthocyanin content (Clark et al., 2002; Kalt and McDonald 1996; Kalt et al., 1999). Antioxidant composition of strawberry varies among cultivars and also with development stage and tissue specificity (Kosar et al., 2004, Maas et al., 1991, Ménager et al., 2004; Olsson et al., 2004). Pulp of immature strawberry fruit was found to contain about twice as much ellagic acid as red fruit pulp and, higher concentration was found in achenes compared to fruit pulp and leaf tissue. Wang and Lin (2000) studied the total antioxidant capacity in strawberry, raspberry and blackberry and reported it as oxygen radical absorbance capacity (ORAC). Their results showed that blackberries and strawberries had higher ORAC activity at the green stage compared to raspberries, and that the anthocyanin content of strawberries and blackberries increased with maturity.

Kalt and co-workers (2001) showed an increase in anthocyanin content and ORAC activity of strawberry and raspberry during $8 \mathrm{~d}$ of storage at temperatures higher than $0^{\circ} \mathrm{C}$. In highbush blueberries (Vaccinium corymbosum L.), Kalt et al. (2003) reported lower phenolic content and ORAC activity in the ripe fruit.

Molecules with antioxidant properties play significant roles in several biological processes that sustain life and defense against external stresses. In plant organs, oxidative stress is involved in physiological processes such as fruit ripening and senescence (Brennan and
Frenkel, 1977; Rogier et al., 1998). Free radicals through the induction of lipid peroxidation play an important role in senescence and ageing process. High levels of cellular antioxidants, particularly of reducing enzymes, were demonstrated to delay senescence in fruit and vegetables species such as muskmelon (Cucumis melo L.), sweet peppers (Capsicum annuum L.) and spinach (Spinacia oleracea L.) (Lancan and Baccou, 1998; Masia, 1998; Miyake et al., 1998). It has been shown that phenolic compounds play an important role in plant defense mechanisms against field and post-harvest infection or injuries (Mayr et al., 1997; Wang et al., 1994). A 3-fold increase in ellagic acid content was observed in raspberry leaves infected by orange rust (Arthuriomyces peckianus) (Wang et al., 1994); and high level of catechins, the main constitutive unit of proanthocyanidins (PA), found in immature strawberry fruits was associated with resistance to grey mold (Botrytis cinerea Pers. ex. Fr.) (Di Venere et al., 1998; Feucht et al., 1992; Jersch et al., 1989). In vitro studies revealed that proanthocyanidins of some strawberry cultivars reduced hyphal growth of grey mold and, fruits of such cultivars high in PA content were more resistant to storage rot development (Hébert et al., 2002).

As underlined by several authors, the antioxidant profile of fruits and vegetables need to be considered in breeding programs, along with field performance and responses of the selections to cultural practices as well as harvest and post-harvest storage strategies (Asami et al., 2003; Gao et al., 2000; Maas et al., 1991; Strålsjö et al., 2003; Wang et al., 2002).

The purpose of this study was to evaluate antioxidant activity and phenolic content of selected cultivars and advanced strawberry selections to find cultivars high in antioxidants for use as parents in future strawberry breeding program.

\section{Materials and Methods}

Chemicals. Phenolic standards and tetramethyl chroman carboxylic acid were purchased from Sigma Chemical Co. (Oakville, Ontario); ellagic acid, gallic acid, $p$-coumaric acid, sodium carbonate $\left(\mathrm{Na}_{2} \mathrm{CO}_{3}\right)$ and the Folin-Ciocalteu reagent were purchased from Sigma Chemical Co. (St. Louis, Mo.); quercetin-3-galactoside was from Fluka Chemie GmbH (Buchs, Switzerland); and cyanidin-3galactoside was from Indofine Chemical Co. (Hillsborough, N.J.). Water used for HPLC analysis was purified in-house from distilled and deionized water using a NanoPure system (Dubuque, Iowa). All other HPLC grade solvents were purchased from Caledon Laboratories Ltd (Georgetown, Ontario).

Sample preparation and extraction procedures. Fruit samples from 18 strawberry genotypes (Fragaria $\times$ ananasa Deuch.) were collected from a completely randomized design with four replications established in Agriculture and Agri-Food Canada experimental farm, located at l'Acadie (longitude 73.35 W; latitude $45.32 \mathrm{~N})$, Quebec. Fruit ( $0.5 \mathrm{~kg}$ fresh weight per replication) were harvested at optimum 
maturity in July 2003. Samples were rapidly cooled to $1^{\circ} \mathrm{C}$, brought to the laboratory where they were cut in half, frozen in liquid nitrogen and three subsamples of $150 \mathrm{~g}$ of each genotype were stored at $-80^{\circ} \mathrm{C}$ until extraction. Samples were lyophilised in Lyo-Tech freeze-dryer (Lyo-San Inc., Quebec, Canada), and an aliquot of each subsample was used to determine the average dry/fresh matter ratio of $10 \%$. Freeze dried samples were reduced to a fine powder with a commercial coffee grinder and stored at $-20^{\circ} \mathrm{C}$ until analysis.

All data were subjected to an Analysis of Variance (ANOVA) using GLM and CORR procedure of SAS (1989). The means were separated using the least significant difference (LSD) test at 0.05 level.

Freeze-dried samples. Ground freeze-dried sample ( $1 \mathrm{~g})$ was homogenized in a blender (Power Gen 700) for $2.5 \mathrm{~min}$ with $50 \mathrm{~mL}$ deionized water on ice $\left(4{ }^{\circ} \mathrm{C}\right)$. Three extracts were prepared according to the procedure described by Gao et al. (2000). Briefly, $5 \mathrm{~mL}$ of the original homogenized sample were diluted with $1 \mathrm{~mL}$ of $95 \% \mathrm{EtOH}$. The mixture was centrifuged at $4{ }^{\circ} \mathrm{C}$ (4500 rpm, $\left.15 \mathrm{~min}\right)$, and the clear supernatant was collected as crude extract. The aqueous and lipophilic extracts were obtained after partitioning with $95 \%$ ethanol and hexane.

The original homogenized sample $(5 \mathrm{~mL})$ was also diluted with $1 \mathrm{~mL}$ of EtOH $95 \%$ and extracted twice with hexane $(2 \times 4 \mathrm{~mL})$. The hexane phase was dried under nitrogen, redissolved in $6 \mathrm{~mL}$ of EtOH $95 \%$ and used as lipophilic extract. The aqueous phase was then centrifuged at $4{ }^{\circ} \mathrm{C}$ and at $4500 \mathrm{rpm}$ for $15 \mathrm{~min}$. Strawberry samples of this extraction procedure were used for ABTS cation radicalscavenging assay.

Frozen samples. Ten grams (10 g) of fresh-frozen fruit were blended in $50 \mathrm{~mL}$ of $50 \%$ methanol using a Polytron blender (Brinkmann Instruments, New York). The mixture was filtered through filter paper(Whatman no. 1) and through a $0.45-\mu \mathrm{m}$ Acrodisc syringe filter (Gelman Lab., Michigan). The final filtrate was then stored at $-20{ }^{\circ} \mathrm{C}$ before being analyzed. Extracts resulting from this procedure were used in total phenolic content, ferric reducing/antioxidant power (FRAP) and HPLC assays.

ABTS cation radical-scavenging assay. The ABTS (2,2'-azinobis (3-ethylbenzothiazoline6-sulfonic acid) free-radical-scavenging assay was conducted as described by Pellegrini et al. (1999). ABTS stock solution was prepared by mixing $5 \mathrm{~mL}$ of $7 \mathrm{~mm}$ (ABTS) with $88 \mu \mathrm{L}$ of $140 \mathrm{~mm} \mathrm{~K} \mathrm{~S}_{2} \mathrm{O}_{8}$. The stock solution was diluted with $95 \%$ EtOH to give an absorbance of $0.7 \pm 0.05$ at $734 \mathrm{~nm}$. Strawberry extracts $\left(5 \mu \mathrm{L}\right.$ of $16 \mathrm{mg} \cdot \mathrm{mL}^{-1}$ ) were mixed with $1 \mathrm{~mL}$ ABTS reagent and measured at $734 \mathrm{~nm}$ (Beckman 600) after $30 \mathrm{~min}$ at room temperature. Trolox (a water soluble vitamin E analogue) was used as a standard and the capacity of free radical scavenging was expressed as $\mu \mathrm{mol}$ trolox equivalents (TE) per gram of dry matter $\left(\mu \mathrm{mol} \cdot \mathrm{g}^{-1}\right)$.

Ferric reducing/antioxidant power assay. The FRAP was determined according to the method of Benzie and Strain (1996) which was modified for the 96-well microplate reader (Tsao et al., 2003a). $\mathrm{FeSO}_{4}$ was used as standard and the FRAP value of the samples was calculated on the basis of $500 \mu \mathrm{M} \mathrm{Fe}{ }^{2+}$ $\left(\mathrm{FeSO}_{4} \cdot 7 \mathrm{H}_{2} \mathrm{O}\right)$.

Total phenolic content. Total phenolic content was determined according to the Folin-Ciocalteu (FC) method (Slinkard and Singleton, 1977) with slight modifications. Briefly, the standard or sample extract $(0.2 \mathrm{~mL})$ were mixed with $1.0 \mathrm{~mL}$ of Folin-Ciocalteu reagent and $0.8 \mathrm{~mL}$ of $\mathrm{Na}_{2} \mathrm{CO}_{3}(7.5 \%)$ and allowed to stand for $30 \mathrm{~min}$ at room temperature. Absorption was measured at $765 \mathrm{~nm}$ in a spectrometer (Cary 3C; Varian Canada Inc., Ontario). Gallic acid was used as a standard and the total phenolic content was expressed as gallic acid equivalents (GAE) in $\mu \mathrm{g} \cdot \mathrm{g}^{-1}$ of fresh-frozen fruit.

Phytochemical content (HPLC). The phenolic composition of berries was analyzed by HPLC as described by Tsao and Yang (2003). The injection volume was $20 \mu \mathrm{L}$ for all samples. All standards except for anthocyanins were dissolved in methanol. The latter were dissolved in $1 \% \mathrm{HCl}$ in methanol. The detector was set at 254, 280, 320,360, and $520 \mathrm{~nm}$ for simultaneous monitoring of the different groups of phenolics.

Total phenolic compounds were divided into five groups, as follows: anthocyanins were quantified using cyanidin-3-galactoside (520 $\mathrm{nm})$, hydroxycinnamic acids were quantified using p-coumaric acid (320 nm), flavonols were quantified using quercetin-3-galactoside (360 $\mathrm{nm})$, for ellagic acid the authentic standard was used $(254 \mathrm{~nm})$ and benzoic acids were quantified using gallic acid $(280 \mathrm{~nm})$ (Tsao et al., 2003b; Wang et al., 2002). The results were expressed as $\mu \mathrm{g} \cdot \mathrm{g}^{-1}$ fresh-frozen fruit.

\section{Results}

ABTS cation radical-scavenging assay. Significant differences in TEAC were observed among the selected genotypes (Table 1). For all genotypes, the antioxidant capacity measured by the ABTS cations radical-scavenging assay was higher for the crude and aqueous extracts than for lipophilic ones (Table 1). Total antioxidant capacity ranged from 198.8 to $272.4 \mu \mathrm{mol} \cdot \mathrm{g}^{-1}$ and 214.3 to $263.1 \mu \mathrm{mol} \cdot \mathrm{g}^{-1}$ of TE for the crude and aqueous extracts, respectively. Total antioxidant capacity of the lipophilic extracts varied from 26.0 to $40.3 \mu \mathrm{mol} \cdot \mathrm{g}^{-1}$ of TE. The highest TEAC value of crude extracts was found for genotypes 'APF9335-26' (272.4 $\left.\mu \mathrm{mol} \cdot \mathrm{g}^{-1}\right)$, and 'Jewel' $\left(269.5 \mu \mathrm{mol} \cdot \mathrm{g}^{-1}\right)$, while 'Kent' had the lowest TEAC $\left(198.8 \mu \mathrm{mol} \cdot \mathrm{g}^{-1}\right)$.

Similar to the crude extracts, the highest TEAC of aqueous extracts were recorded for 'APF9335-26' and 'Jewel' (263.1 and 259.3 $\mu \mathrm{mol} \cdot \mathrm{g}^{-1}$ ) followed by 'Orléans' and 'FIO996-2' with an equivalent amount (Table 1). In contrast, low antioxidant capacity was found for 'Clé des Champs' and 'SJ8976-1' genotypes (214.3 and $217.9 \mu \mathrm{mol} \cdot \mathrm{g}^{-1}$, respectively). The genotypes 'FIO9917-25', 'Saint-Jean d'Orléans', and 'Saint Pierre' were intermediate for both crude and aqueous extracts. The lipophilic extracts showed the lowest activity when compared to the other extracts but showed greater variation among genotypes. The TEAC value from 'SaintLaurent d'Orléans' and 'Jewel'was significantly higher (40.3 and $39.9 \mu \mathrm{mol} \cdot \mathrm{g}^{-1}$, respectively), than that of 'Harmonie' $\left(26.0 \mu \mathrm{mol} \cdot \mathrm{g}^{-1}\right)$.

Ferric reducing/antioxidant power assay. Great differences $(p<0.0001)$ among genotypes were found in their ferric reducing ability (Table 1). On the basis of the standard $\left(\mathrm{Fe}^{2+}\right)$, 'FIO9923-7', 'APF9335-26' and 'Jewel' genotypes showed the highest antioxidant activity (2984, 2963, and $2874 \mu$ MFRAP, respectively). Conversely, 'Kent' had the lowest activity with $2131 \mu \mathrm{M}$ FRAP. For most of the remaining genotypes, FRAP values varied between 2400 and $2200 \mu \mathrm{M}$ (Table 1).

Total phenolic content. Significant differences were observed between the genotypes tested $(p<0.0001)$ in total phenolic content. The total phenolic content ranged from 426.5 to $937.1 \mu \mathrm{g} \cdot \mathrm{g}^{-1}$. Fruit of 'Jewel', 'Harmonie', 'APF9335-26', 'Saint-Laurent d'Orléans', 'FIO9923-7' and 'Clé des Champs' had the highest total phenolic content with $>800$ $\mu \mathrm{g} \cdot \mathrm{g}^{-1}$ (Table 1), whereas 'FIO9917-25' selection had the lowest total phenolic content with less than $500 \mu \mathrm{g} \cdot \mathrm{g}^{-1}$. The remaining genotypes were intermediate with a total phenolic content varying between 550 and

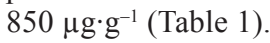

There was a positive correlation between FRAP and total phenolic content of the fruits $(r$ $=0.6599, p<0.05)$. The higher total phenolic content in fruits resulted in higher total antioxidant activity. However, a weak correlation was observed between TEAC (crude extract) and total phenolic content $(r=0.4438, p<0.05)$. A positive correlation was also noted between FRAP and TEAC (crude extract) antioxidant capacity $(r=0.6625, p<0.05)$.

Phenolic composition. Among the five groups, the anthocyanins were the most predominant phenolic compounds in strawberry extracts (67.2\% of the total phenolics) (Table 2$)$. Once again, 'Jewel' contained up to $800 \mu \mathrm{g} \cdot \mathrm{g}^{-1}$ (cyanidin-3-galactoside equivalent) followed by 'Clé des Champs' and 'APF9926-27' with 686.79 and $659.31 \mu \mathrm{g} \cdot \mathrm{g}^{-1}$. The lowest values were found for 'APF9335-26', 'FIO9917-25' and 'SJ8976-1' (190.5, 245.5 and 252.33 $\mu \mathrm{g} \cdot \mathrm{g}^{-1}$, respectively).

Benzoic acids were the second group in abundance with $16.8 \%$ of the total phenolics. 'FIO9917-25' and 'APF9335-26' had the highest content of benzoic acids ( 245.58 and 211.47 $\mu \mathrm{g} \cdot \mathrm{g}^{-1}$ gallic acid equivalent, respectively).

Hydroxycinnamic acids group levels ranged between 143.91 to $16 \mu \mathrm{g} \cdot \mathrm{g}^{-1}$, with the highest amounts being recorded in 'Harmonie' and 'APF9323-7' (143.91 and $141.96 \mu \mathrm{g} \cdot \mathrm{g}^{-1} \mathrm{p}$-coumaric acid equivalent) followed by 'FIO991329', 'SJ8976-1', and 'Orléans'(Table 2). The lowest amount was measured in 'FIO9917-25' $\left(16.38 \mu \mathrm{g} \cdot \mathrm{g}^{-1}\right)$.

Flavonols content ranged from 51.78 to $11.55 \mu \cdot \mathrm{g}^{-1}$ quercetin-3-galactoside equivalent and ellagic acid from 33.96 to $14.31 \mu \mathrm{g} \cdot \mathrm{g}^{-1}$. These two groups recorded the lowest contribution with $4.8 \%$ and $3 \%$ of the total pheno- 
lics, respectively. 'FIO996-2', 'FIO9923-7', 'APF9926-27', 'APF9323-7', 'Harmonie', and 'Saint-Jean d'Orléans' had higher flavonols amount while 'APF9335-26' and 'Saint-Jean d'Orléans' showed the highest and the lowest ellagic acid amount, respectively.

The amount of total phenolics in the frozen fruits analyzed by HPLC ranged between 1014.99 and $482.94 \mu \mathrm{g} \cdot \mathrm{g}^{-1}$. The highest total phenolics content was found for 'Jewel' followed by 'Clé des Champs', 'APF9926-27', 'APF9323-7' and 'Harmonie' (Table 2).

No correlation was found between ellagic acid, anthocyanins content and total antioxidant capacity (TEAC, FRAP).

\section{Discussion}

Crude extract contained both hydrophilic (aqueous extract) and lipophilic antioxidants. As illustrated in the present study, the aqueous extract markedly contributes to the total antioxidant capacity and could be related to the total phenolic content. A positive correlation between free phenolics and total antioxidant activity in a number of different fruit has been reported (Kalt et al., 2003; Wang and Lin, 2000). In our study phenolics account for a major portion of the total antioxidant activity of strawberries $(r=0.6599, p<0.05)$.

The contents of total phenolics, as deter- mined by the FC assay, for the fruit extract analyzed here, were in the same range $(86 \mathrm{mg}$ GAE/100g FW) of those reported by Kalt et al. (1999). However, they were relatively lower than those reported by Tsao et al. (2003b) and Funt et al. (2001), whereas the FRAP values were in the range of reported results. The large differences in total phenolic content are probably due to the different genotypes used. Wang and Lin (2000) reported that the total phenolic content in different varieties of ripe strawberry fruit ranged from 95 to $152 \mathrm{mg}$ GAE/100 g FW.

The literature provides variable figures for the total antioxidant capacity of strawberry fruit

Table 1. Antioxidant capacity and total phenolic content of 8 cultivars and 10 advanced strawberry selections grown at the L'Acadie site.

\begin{tabular}{|c|c|c|c|c|c|}
\hline \multirow[b]{3}{*}{ Genotype } & \multicolumn{4}{|c|}{ Total antioxidant capacity ${ }^{z}$} & \multirow{3}{*}{$\begin{array}{c}\text { Content } \\
\text { Total phenolic }{ }^{\mathrm{w}} \\
(\mu \mathrm{g} \text { GAE } / \mathrm{g}) \\
\text { Crude }\end{array}$} \\
\hline & \multicolumn{3}{|c|}{$\begin{array}{c}\text { TEAC }^{\mathrm{y}} \\
(\mu \mathrm{mol} \mathrm{TE} / \mathrm{g})\end{array}$} & \multirow{2}{*}{$\begin{array}{c}\text { FRAP }^{x} \\
(\mu \mathrm{M}) \\
\text { Crude }\end{array}$} & \\
\hline & Crude & Aqueous & Lipophilic & & \\
\hline Saint-Jean d'Orléans & 227.4 & 234.7 & 29.5 & 2044.9 & 647.1 \\
\hline Saint-Laurent d'Orléans & 242.5 & 248.0 & 40.3 & 2478.4 & 836.5 \\
\hline Orléans & 202.0 & 259.1 & 27.8 & 2164.5 & 629.9 \\
\hline Clé des Champs & 225.9 & 214.3 & 29.1 & 2622.7 & 804.3 \\
\hline Harmonie & 239.9 & 224.4 & 26.0 & 2752.2 & 857.0 \\
\hline Saint Pierre & 232.9 & 232.7 & 32.5 & 2194.8 & 598.2 \\
\hline Jewel & 269.5 & 259.3 & 39.9 & 2873.9 & 937.1 \\
\hline Kent & 198.8 & 228.6 & 29.7 & 2131.5 & 636.3 \\
\hline FIO9917-25 & 222.8 & 241.4 & 28.8 & 2181.8 & 426.5 \\
\hline FIO9926-47 & -- & -- & --- & 2364.2 & 663.3 \\
\hline FIO9913-29 & --- & --- & --- & 2280.3 & 593.5 \\
\hline FIO9923-7 & --- & --- & --- & 2984.3 & $808 \mathrm{q} .0$ \\
\hline FIO996-2 & 252.1 & 259.4 & 31.3 & 2686.1 & 731.2 \\
\hline APF9926-27 & --- & --- & --- & 2425.9 & 762.3 \\
\hline APF937-1 & 208.2 & 230.9 & 27.8 & --- & --- \\
\hline APF9335-26 & 272.4 & 263.1 & 35.8 & 2963.1 & 856.7 \\
\hline SJ8976-1 & 239.5 & 217.9 & 26.9 & 2458.7 & 708.1 \\
\hline APF9323-7 & --- & --- & -- & 2546.0 & 742.2 \\
\hline LSD $5 \%$ & 43.8 & 31.5 & 5.88 & 319 & 154 \\
\hline$P>\mathrm{F}$ & $<0.0002$ & 0.0034 & 0.0002 & $<0.0001$ & $<0.0001$ \\
\hline
\end{tabular}

${ }^{z}$ Values are means of three to four replications.

${ }^{y} \mathrm{TEAC}=$ trolox equivalent antioxidant capacity expressed as $\mu \mathrm{mol}$ trolox equivalents (TE) per g dry matter.

${ }^{x} \mathrm{FRAP}=$ ferric-reducing antioxidant power expressed as $\mu \mathrm{M}$ FRAP.

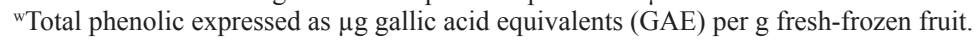

Table 2. Phenolic composition $\left(\mu \mathrm{g} \cdot \mathrm{g}^{-1}\right.$ fresh-frozen fruit) in eight cultivars and nine advanced strawberry selections grown at the L'Acadie site.

\begin{tabular}{|c|c|c|c|c|c|c|}
\hline Genotype & $\begin{array}{c}\text { Total } \\
\text { anthocyanins } \\
(520 \mathrm{~nm})\end{array}$ & $\begin{array}{c}\text { Total } \\
\text { hydroxycinnamic } \\
\text { acids } \\
(320 \mathrm{~nm})\end{array}$ & $\begin{array}{c}\text { Total } \\
\text { flavonols } \\
(360 \mathrm{~nm})\end{array}$ & $\begin{array}{l}\text { Ellagic } \\
\text { acid } \\
(254 \mathrm{~nm})\end{array}$ & $\begin{array}{c}\text { Total } \\
\text { benzoic } \\
\text { acids } \\
(280 \mathrm{~nm})\end{array}$ & $\begin{array}{c}\text { Total } \\
\text { phenolics } \\
\text { Sum } \\
\text { of five } \\
\text { groups }\end{array}$ \\
\hline Saint-Jean d'Orléans & 363.39 & 42.27 & 43.11 & 14.31 & 84.09 & 547.17 \\
\hline Saint-Laurent d'Orléans & 427.85 & 29.10 & 28.98 & 22.68 & 38.40 & 587.01 \\
\hline Orléans & 392.19 & 86.97 & 15.21 & 19.69 & 116.07 & 629.13 \\
\hline Clé des Champs & 686.79 & 35.31 & 26.85 & 15.81 & 163.14 & 927.90 \\
\hline Harmonie & 463.41 & 143.91 & 45.21 & 21.90 & 82.47 & 756.84 \\
\hline Saint Pierre & 448.74 & 54.93 & 29.97 & 16.65 & 56.13 & 606.42 \\
\hline Jewel & 841.26 & 26.01 & 38.37 & 15.75 & 93.63 & 1014.99 \\
\hline Kent & 622.89 & 23.97 & 25.38 & 23.76 & 64.56 & 760.53 \\
\hline FIO9917-25 & 245.55 & 16.38 & 18.48 & 19.59 & 245.58 & 545.61 \\
\hline FIO9926-47 & 542.43 & 65.19 & 40.83 & 20.28 & 73.29 & 742.02 \\
\hline FIO9913-29 & 364.89 & 92.88 & 29.73 & 20.43 & 117.84 & 625.77 \\
\hline FIO9923-7 & 497.94 & 50.55 & 50.46 & 22.02 & 102.36 & 723.36 \\
\hline FIO996-2 & 509.10 & 22.83 & 51.78 & 22.62 & 124.74 & 731.10 \\
\hline APF9926-27 & 659.31 & 54.99 & 47.07 & 19.08 & 77.25 & 857.70 \\
\hline APF9335-26 & 190.50 & 27.90 & 19.11 & 33.96 & 211.47 & 482.94 \\
\hline SJ8976-1 & 252.33 & 90.03 & 11.55 & 23.91 & 148.98 & 526.83 \\
\hline APF9323-7 & 405.75 & 141.96 & 43.83 & 19.41 & 175.50 & 786.42 \\
\hline Mean & 465.55 & 61.70 & 33.29 & 20.78 & 116.21 & 693.20 \\
\hline Percent & 67.2 & 8.0 & 4.8 & 3.0 & 16.8 & 100 \\
\hline LSD $5 \%$ & 39.07 & 10.1 & 5.34 & 2.18 & 9.32 & 40.08 \\
\hline
\end{tabular}

"2Phenolic groups were quantified as follows: ellagic acid as ellagic acid, benzoic acids as gallic acid, hydroxycinnamic acids as p-coumaric acid, flavonols as quercetin-3-galactoside, and anthocyanins as cyanidin-3-galactoside. 
assessed by the ORAC method. The values of $15.4 \mu \mathrm{M} \mathrm{TE} / \mathrm{g} \mathrm{FW}$ is an accepted average figure for strawberry fruit (Wang et al., 1996) and 20 $\mu \mathrm{M} \mathrm{TE} / \mathrm{g}$ FW was reported for 'Kent' (Prior et al., 1998). Of the total antioxidant capacity reported by Wang et al. (1996) vitamin C contributed for $<15 \%$.

Our preliminary chemical analysis of the fruits using HPLC analysis revealed that anthocyanins (cyaniding-3-glucoside, pelargonidin3 -glucoside) were the most predominant phenolics group in strawberry extracts, followed by benzoic acids (p-hydroxybenzoic, gallic acids), hydroxycinnamic acids (p-coumaric acid, ferulic acid), flavonols (quercetin-3-galactoside) and ellagic acid groups.

A high variation of phenolic contents of strawberry cultivars was found in the literature. Our results show that anthocyanins, ellagic acid, flavonol and hydroxycinnamic acids levels were relatively similar to those reported in strawberry by Wang et al. (2002) and Meyers et al. (2003), but they were higher than those reported for ripe strawberries (Kosar et al., 2004).

No correlation was obtained between individual phenolic compound (especially anthocyanins and ellagic acid) and total antioxidant activity (TEAC, FRAP). Similar results were found by Meyers et al. (2003) in strawberries. They concluded that it was probably due to the other unquantified phenolics and/or synergism among these compounds and major phenolics. On the other hand, several studies showed that principal antioxidant activity of grape, blueberry and strawberry correlated to total phenolics and anthocyanins rather than to any individual compound, independent of the assays used (Prior et al., 1998; Wang and Lin 2000). According to Macheix et al. (1990), strawberries contain numerous phenolic compounds, and not all cultivars contain the same phenolic profile. Furthermore they reported relative proportions of compounds within the profile and differences within these profiles might subsequently result in complex changes in antioxidant activity or other bioactivities.

It is generally accepted that antioxidants act to extend shelf life and enhance quality preservation of fresh fruit by delaying senescence induced by oxidative degradation (Brennan and Frenkel, 1977; Lancan and Baccou, 1998; Masia, 1998; Miyake et al., 1998; Rogier etal., 1998). High levels of cellular antioxidants are presumed to play an important role in delayed senescence observed in nonnetted muskmelon fruits (Lacan and Baccou, 1998). The fruit of 'Orléans' has a very good shelf life of over $5 \mathrm{~d}$ at $4{ }^{\circ} \mathrm{C}$ (Khanizadeh et al., 2003), and the preliminary study on this cultivar indicate higher levels of free epicatechin, bound catechin, epicatechin and ellagic acid (Hébert et al., 2002). In the present study, high antioxidant capacity (TEAC and FRAP) was found for 'Harmonie', 'Saint-Jean d'Orléans' and 'Saint-Laurent d'Orléans', which exhibit better shelf life stability than 'Kent' (Khanizadeh et al., 2005; Khanizadeh, 2003a, 2003b, 2003c). It seems that there might be an association between antioxidant capacity and postharvest quality preservation as demonstrated for other crops
(Baldwin etal., 1995; Khan etal., 1999; Lancan and Baccou, 1998; Masia, 1998; Miyake et al., 1998), however this is not always straight forward. For example 'Saint Pierre' characterized by very good shelf life (Khanizadeh et al., 2002) displayed similar level of antioxidants (gallic acid, epicatechin, catechin and ellagic acid) to other cultivars with shorter shelf life (Hébert et al., 2002).

Disease development is one of the principal causes of premature termination of postharvest shelf life of strawberries. Numerous studies have conclusively established a key role for constitutive and induced phenolic compounds in defense of plant tissues against pathogen attacks (Nicholson and Hammerschmidt, 1992; Prusky, 1996). Phenolic compounds, such as catechin, and the main constitutive unit of proanthocyanidins (PA), which are oligomers of flavan-3-ols, were associated to Botrytis cinerea resistance (Di Venere et al., 1998; Feucht et al., 1992). Hébert et al. (2002) evaluated in vitro the inhibition of grey mold growth of six strawberry cultivars and found that 'Seascape' PA extract gave the highest inhibition of mold radial growth $(76.2 \%)$ and its fruit was also the most resistant to the appearance of mold during storage $(22 \mathrm{~d})$ with excellent shelflife. 'Harmonie'(Khanizadeh et al., 2005) 'Saint-Jean d'Orléans' (Khanizadeh, 2003b) and 'Orléans' (Khanizadeh et al., 2003), all being more resistant to diseases and some disease resistant advanced lines ('FIO991329', 'SJ8976-1', 'FIO9917-25', 'APF933526', 'FIO9923-7', and 'FIO996-2') were higher in hydroxycinnamic acids, benzoic acids, and flavonols than 'Kent' (Table 2). It seems that there is a possibility that low susceptibility of these cultivars to diseases might be due to their antioxidant activity and/or phenolic compounds as demonstrated previously on other crop species (Mayr et al., 1997; Wang et al., 1994). According to these authors, phenolics were the main compounds involved in the effective defense of plant tissues (i.e., mayhaws berries and apples) against field and postharvest infection or injuries and were significantly more active individually than in combination. It has been shown that benzoic acids have antibacterial, antifungal and antioxidant properties to prevent food spoilage and to enhance quality and shelf life (Baldwin et al., 1995; Khan et al., 1999). Lindhard Pedersen (2003) found that resistance to the diseases of five black currant (Ribes nigrum L.) cultivars was correlated with their high levels of hydroxycinnamic acid derivatives. Moreover, these acids can react with organic molecules such as amino acids to synthesize secondary metabolites that become highly toxic to the pathogen (Nicholson and Hammerschmidt, 1992).

In summary, our results show a significant variation in antioxidant capacity and total phenolic compound in selected strawberry genotypes and this investigation clearly shows the potential value of certain new cultivars and advanced lines and their possible use in breeding programs. Moreover, development of new strawberry fruit with higher antioxidant capacity may not only enhance resistance to diseases and increase shelf life but also stimulate greater interest in the nutraceutical and functional food aspects to strawberry consumption and potentially help to reduce risks of cancers and heart diseases (Galati et al., 2004; Halliwell, 1997; Liu, 2003; Maas et al., 1991).

\section{Literature Cited}

Asami D.K., Y.J. Hong, D.M. Barrett, and A.E. Mitchell. 2003. Comparison of the total phenolic and ascorbic acid content of freeze-dried and air-dried Marion berry, strawberry, and corn grown using conventional, organic, and sustainable agricultural practices. J. Agr. Food Chem. 51:1237-1241.

Baldwin E.A., M.O. Nisperos Carriedo, and R.A. Baker. 1995. Use of edible coatings to preserve quality of lightly processed products. Crit. Rev. Food Sci. Nutr. 35:509-24.

Benzie, I. and J.J. Strain. 1996. The ferric reducing ability of plasma (FRAP) as a measure of "antioxidant power": The FRAP assay. Anal. Biochem. 239:70-76.

Brennan, T. and C. Frenkel. 1977. Involvement of hydrogen peroxide in the regulation of senescence in pear. Plant Physiol. 59:411-416.

Clark, J.R., L. Howard, and S. Talcott. 2002. Variation in phytochemical composition of blueberry cultivars and breeding selections. In: Proceeding of the VII International Symposium on Vaccinium Culture. Acta Hort. 574:203-207

Di Venere D., V. Linsalata, A. Ippolito, F. Nigro, P. Arcuti, and V. Lattanzio. 1998. Endogenous phenolic, ripening and susceptibility of strawberry fruits (Fragaria $\times$ ananassa Duch.) to post-harvest diseases. In: 2nd Intl. Electronic Conf. on Synthetic Organic Chemistry (ECSOC-2). http:// ecsoc2.hcc.ru/DP_TOP4/dp224/dp224.htm

Feucht, W., E. Treutter, and E. Christ. 1992. The precise localization of catechins and proanthocyanidins in protective layers around fungal infections. J. Plant Dis. Prot. 99 (4):404-413.

Funt, R.C., S.J. Schwartz, and W. Bash. 2001. Evaluation of ellagic acid content of Ohio berries-Final report. Ohio State Univ. Ext. http://www.ag.ohiostate.edu/ sfgnet/eacid_final.html.

Gao, X., M. Ohlander, N. Jeppsson, L. Bjork, and V. Trajkovski. 2000. Changes in antioxidant effects and their relationship to phytonutrients in fruits of sea buckthorn (Hippophae rhamnoides L.) during maturation. J. Agr. Food Chem. 48:1485-1490.

Galati, G and P.J. O'Brien 2004. Potential toxicity of flavonoids and other dietary phenolics: significance for thier chemoproventive and anticancer properties. Free Radical Biol. Med. 37(3):287-303.

Halliwell, B. 1997. Antioxidants and human disease: a general introduction. Nutr. Rev. 55:44-52.

Hébert, C., M.T. Charles, L. Gauthier, C. Willemot, S. Khanizadeh, and J. Cousineau. 2002. Strawberry Proanthocyanidins: Biochemical markers for Botrytis cinerea resistance and shelf life predictability. Acta Hort. 567:659-662.

Jersch, S., C. Scherer, G. Huth, and E. Schlosser. 1989. Proanthocyanidins as basis for quiescence of Botrytis cinerea in immature strawberry fruits. J. Plant Dis. Prot. 96 (4):365-378.

Kalt, W. and J.E. McDonald. 1996. Chemical composition of lowbush blueberry cultivars. J.Amer. Soc. Hort. Sci. 121:142-146.

Kalt, W., C.F. Forney, A. Martin, and R.L. Prior. 1999. Antioxidant capacity, vitamin C, phenolics, and anthocyanins after fresh storage of small fruits. J. Agr. Food Chem. 47:4638-4644.

Kalt, W., A. Howell, J.C. Duy, C.F. Forney and J.E. McDonald. 2001. Horticultural factors affecting antioxidant capacity of blueberries and other 
small fruit. HortTechnology 11(4):523-528.

Kalt, W., C. Lawand, D.A.J. Ryan, J.E. McDonald, H. Donner, and C.F. Forney. 2003. Oxygen radical absorbing capacity, anthocyanin and phenolic content of highbush blueberries (Vaccinium corymbosum L.) during ripening and storage. J. Amer. Soc. Hort. Sci. 128(6):917-923.

Khan, S.H., J. Aked, and N. Magan. 1999. The potential for antioxidant chemicals to control Colletotrichum musae on banana fruit. 51 International Symposium on Crop Protection, Gent (Belgium). 64(3b):531-537.

Khanizadeh, S., J. Cousineau, M. Deschênes, A. Levasseur, O. Carisse, J. DeEll, L. Gauthier, and A. Sullivan. 2002. 'Saint-Pierre'strawberry. HortScience 37(7):1133-1134.

Khanizadeh, S. 2003a. An overview of the Quebec strawberry breeding program of Agriculture and Agri-Food Canada at St-Jean-sur-Richelieu, Quebec: Past and present achievements and future objectives. Adv. Strawberry Prod. vol. 21-22:1-7.

Khanizadeh, S. 2003b. St-Jean d'Orléans. Plant Var. J. 46:184-185.

Khanizadeh, S. 2003c. St-Laurent d'Orléans. Plant Var. J. 46:185-186.

Khanizadeh, S., O. Carisse, M. Deschenes, J. DeEll, L. Gauthier, A. Gosselin, D. Buszard, and C. Rong. 2003. 'Orléans' Strawberry. Adv. Strawberry Prod. vol. 21-22:9-11.

Khanizadeh, S., M. Deschenes, A. Levasseur, O. Carisse, M.T. Charles, D. Rekika, R. Tsao, R. Yang, J. DeEll, P. Thibeault, J.P. Privé, C. Davidson, and B. Bors. 2005. 'Harmonie' strawberry. HortScience 40(2):480-481.

Kosar M., E. Kafkas, S. Paydas, and K.H. Can Baser. 2004. Phenolic composition of strawberry genotypes at different maturation stages. J. Agr. Food Chem. 52:1586-1589.

Lancan, D. and J.C. Baccou. 1998. High levels of antioxidant enzymes correlate with delayed senescence in nonnetted muskmelon fruits. Planta 204:377-382.

Pedersen, L.. 2003. http://www.darcof.dk/research/ darcofi/ii1.html.

Liu, R.H. 2003. Health benefits of fruits and vegetables are from additive and synergistic combination of phytochemicals. Amer. J. Clin. Nutr. 78:517S-520S.

Maas, J.L., G.J. Galletta, and G.D. Stoner.1991. Ellagic acid an anticarcinogen in fruits, especially in strawberries: A review. HortScience 26(1):10-14.

Macheix, J.J., A. Fleuriet, and J. Billot. 1990. Fruit phenolics. CRC Press, Boca Raton, Fla.
Masia, A. 1998. Superoxide dismutase and catalase activities in apple fruit during ripening and postharvest and with special reference to ethylene. Physiologia Plantarum 104:668-672.

Mayr, U., S. Michalek, D. Treutter, and W. Feucht. 1997. Phenolic compounds of apple and their relationship to scab resistance. J. Phytopathol. 145:69-75.

Ménager I., M. Jost, and C. Aubert. 2004. Changes in physicochemical characteristics and volatile constituents of strawberry (cv. Cigaline) during maturation. J. Agr. Food Chem. 52:1248-1254.

Myer,A.S., O.S. Yi, D.A. Pearson, A.L. Waterhouse, and E.N. Frankel. 1997. Inhibition of human low density lipoprotein oxidation in relation to composition of phenolic antioxidation in grappes (Vitis vinifera L.). J. Agr. Food Chem. 45:1638-1643.

Meyers, K.J., C.B. Watkins, M.P. Pritts, and R.H. Liu. 2003. Antioxidant and antiproliferative activities of strawberries. J. Agr. Food Chem. 51:6887-6892.

Miyake, C., H. Schreiber, S. Hormann, K. Sano, and K. Asada. 1998. The FAD-enzyme monodehydroascorbate radical reductase mediates photoproduction of superoxide radicals in spinach thylakoid membranes. Plant Cell. Physiol. 39 (8):821-829.

Nicholson, L. and R. Hammerschmidt. 1992. Phenolic compounds and their role in disease resistance. Annu. Rev. Phytopathol. 30:369-389.

Olsson, M.E., J. Ekvall, K.E. Gustavsson, J. Nilsson, D. Pillai, I. Sjöholm, U. Svensson, B. Akesson, and M.G.L. Nyman. 2004. Antioxidants, low molecular weight carbohydrates, and total antioxidant capacity in strawberries (Fragaria $\times$ ananassa): effects of cultivar, ripening, and storage. J. Agr. Food Chem. 52:2490-2498.

Pellegrini, N., R. Re, M. Yang, and C. Rice-Evans. 1999. Screening of dietary carotenoids and carotenoid-rich fruit extracts for antioxidant activities applying 2,2'-azinobis (3-ethylenebenzothiazoline-6-sulfonic acid) radical cation decolorization assay. Meth. Enzym. 299:379-389.

Prior, R., G. Cao, A. Martin, E. Sofic, J. McEwen, C. O'Brien, N. Lischner, M. Ehlenfeldt, W. Kalt, G. Krewer, and C. Mainland. 1998. Antioxidant capacity as influenced by total phenolic and anthocyanin content, maturity, and variety of Vaccinium species. J. Agr. Food Chem. 46:2686-2693.

Prusky, D. 1996. Pathogen quiescence in postharvest diseases. Annu. Rev. Phytopathol. 34:413-434.

Rogier, S.Y., G.N. Mohan Kumar, and N.R.
Knowles. 1998. Maturation and ripening of fruit of Amelanchier alnifolia Nutt. are accompanied by increasing oxidative stress. Ann. Bot. 81:203-211.

SAS Institute. 1989. SAS user's guide: Statistics. version 6. SAS Inst. Cary, N.C.

Saure. 1990. External control of anthocyanin formation in apple. Scientia Hort. 42:181-218.

Slinkard, K. and V.L. Singleton. 1977. Total phenol analysis:Automation and comparison with manual methods. Amer. J. Enol. Viticult. 28:49-55.

Strålsjö L.M., C.M. Witthöft, I.M. Sjöholm, and M.I. Jägerstad. 2003. Folate content in strawberries (Fragaria $\times$ ananassa): Effects of cultivar, ripeness, year of harvest, storage, and commercial processing. J. Agr. Food Chem. 51:128-133.

Tsao, R., R. Yang, and J. C. Young. 2003a. Antioxidant isoflavones in Osage Orange, Maclura pomifera (Raf.) Schneid. J. Agr. Food Chem. 51:6445-6451.

Tsao, R. and R. Yang. 2003. Optimization of a new mobile phase to know the complex and real polyphenolic composition: Towards a total phenolic index using high-performance liquid chromatography. J. Chromatogr. A. 1018:29-40.

Tsao, R., R. Yang, E. Socknovie, T. Zhou, and A. Dale. 2003b. Antioxidant phytochemicals in cultivated and wild Canadian strawberry. Acta Hort. (ISHS) 626:25-35.

Wang, S. Y., J.L. Maas, J.A. Payne, and G. Galleta. 1994. Ellagic acid in small fruits, Mayhaws, and other plants. J. Small Fruit Viticult. 2(4):39-49.

Wang, H., G. Cao, and R.L. Prior. 1996. Total antioxidant capacity of fruits. J. Agr. Food Chem. 44:701-705.

Wang, H., G. Cao, and R.L. Prior. 1997. Oxygen radical absorbing capacity of anthocyanins. J. Agr. Food Chem. 45:304-309.

Wang, S.Y. and H.S. Lin. 2000. Antioxidant activity in fruits and leaves of blackberry, raspberry and strawberry varies with cultivar and developmental stage. J. Agr. Food Chem. 48:140-146.

Wang, S.Y. and W. Zheng. 2001. Effect of plant growth temperature on antioxidant capacity in strawberry. J. Agr. Food Chem. 49(10):49774982

Wang S.Y., W. Zheng, and G.J. Galletta. 2002. Cultural system affects fruit quality and antioxidant capacity in strawberries. J. Agr. Food Chem. 50:6534-6542.

Wang, S.Y., J.A. Bunce and J.L. Maas. 2003. Elevated carbon dioxide increases contents of antioxidant compounds in field-grown strawberries. J. Agr. Food Chem. 51:4315-4320. 